\title{
Elaboração e compressão de sentenças complexas em Guajá
}

\section{Elaboration and compression of complex sentences in Guajá}

\author{
Marina Maria Silva MAGALHÃES* \\ Universidade de Brasília (UNB)
}

RESUMO: Levando-se em consideração o conceito de elaboração e compressão (Lehmann, 1989) como representando dois polos de um continuun de integração entre orações, analiso neste estudo as alterações observadas em orações subordinadas adverbiais do Guajá, conhecidas tradicionalmente pelo termo "gerúndio" (Anchieta ([1595] 1990), Rodrigues (1953), Leite (1978) e Seki (2000)), quando comparadas a outras línguas da família Tupi-Guarani. Para isso, descrevo a relação desta construção com o surgimento de Construções Verbais Seriais (SVCs) em Guarani-Paraguaio (Velázquez-Castillo, 2004) e Emerillón (Rose, 2009) e a gramaticalização de verbos em partículas posicionais e direcionais em Guajá (Magalhães, 2019). Adicionalmente, apresento a hipótese sobre a existência de um tipo de SVC assimétrica no Guajá, restrita a apenas 4 verbos na posição V2, que seriam o que restou de uma estrutura de predicado complexo na língua que está desaparecendo devido ao processo de gramaticalização de verbos em partículas, representando um outro tipo de compressão atestado na língua.

PALAVRAS-CHAVE: Guajá. Orações adverbiais. Ligação entre orações. Compressão. Gramaticalização.

ABSTRACT: Considering the concepts of elaboration and compression (Lehmann, 1989) as representing two ends of a continuum of linkage between clauses, I herein analyze the changes observed in subordinate adverbial clauses in Guajá, traditionally known as "gerund" (Anchieta, 1990; Rodrigues, 1953; Leite, 1978; Seki, 2000), when compared to other languages of the Tupi-Guarani family. For such, I describe the relationship between this construction and the advent of SVCs in Paraguayan Guarani (Velázquez-Castillo, 2004) and Emerillón (Rose, 2009), and the grammaticalization of verbs into positional and directional prepositions in Guajá (Magalhães, 2019). In addition, I put forward the hypothesis of the existence of an asymetric

\footnotetext{
* Graduação em Letras Português - Licenciatura pela Universidade de Brasília, mestrado em Lingüística pela Universidade de Brasília (2002), doutorado em Lingüística pela Universidade de Brasília (2007), pós-doutorado em linguística pelo Centre National de la Recherche Scientifique (CNRS), Paris, França e pós-doutorado na Universidade do Texas em Austin (EUA). http://orcid.org/0000-0003-4231-2582 E-mail: marinamsmag@gmail.com
} 
type of SVCs in Guajá, restricted to only four verbs in the V2 position. This would be what is left of a structure of complex predicates in the language, which is disappearing due to the process of grammaticalization of verbs into particles, representing another type of compression attested in the language.

PALAVRAS-CHAVE: Guajá. Adverbial clauses. Clause linkage. Compression. Grammaticalization.

\section{Introdução}

Em algumas descrições de línguas da família Tupi-Guarani (FTG), como nas do Tupinambá, (Anchieta, 1990; Rodrigues, 1953), Tapirapé (Leite, 1978) e Kamaiurá (Seki, 2000), as orações subordinadas adverbiais são apresentadas pelo termo "gerúndio", mas também já foram tratadas como construção de converb (Rose, 2009), no caso da língua Emerillón. Tais construções caracterizam-se por apresentar um verbo que recebe um sufixo subordinador relacionado a um sistema de switch-reference que marca mesmo sujeito em sequências de predicados com semântica de finalidade, simultaneidade ou sequências de eventos.

Mudanças diacrônicas nessa construção estão relacionadas ao surgimento de Construções Verbais Seriais $\left(\mathrm{SVC}^{1}\right)$ descritas para algumas línguas da FTG, como o Guarani-Paraguaio (Velázquez-Castillo, 2004) e o Emerillón (Rose, 2009), evidenciando a "compressão" (Lehmann 1989, p. 217-218) de uma sentença complexa em um predicado complexo.

No Guajá, uma língua do subgrupo VIII da FTG (Rodrigues, 1984/85; Cabral, 1996) falada por cerca de 520 indivíduos (Garcia e Magalhães, 2021) do povo Awa Guajá, que vive no noroeste do estado do Maranhão, tais orações subordinadas são sincronicamente atestadas (1) e, apesar de não estarem relacionadas ao surgimento de SVCs, também passaram por mudanças que resultaram, de um lado, na perda da construção subordinada para expressar sequências de eventos, evidenciando a “elaboração" (Lehmann, 1989, p. 217-218), isto é, o desdobramento de uma proposição em dois ou mais componentes proposicionais (2) e, de outro lado, na gramaticalização

\footnotetext{
${ }^{1}$ A sigla SVC vem da expressão em inglês Serial Verb Construction.

Revista Moara, n. 58, jan-jul 2021 ISSN: 0104-0944
} 
de verbos de movimento (3) e posicionais (4) em partículas, comprimindo a construção subordinada em um único predicado.

(1) a-wata ta ka'a-pe wari $\emptyset$-ika=pa

1SG.I-caçar PROJ mata-LOC guariba LK-matar=GER

'eu vou caçar na mata para matar guariba'

(2) a-wata ta aha wari-a a-ika ta aha ka'a-pe 1SG.I-caçar PROJ CTF guariba-RFR 1SG.I-matar PROJ CTF mata-LOC 'eu vou caçar (e) vou matar guariba na mata'

(3) ka'i-a Ø-wyhy aha ka'a-pe macaco.prego-RFR 3.I-correr CTF mato- LOC 'O macaco-prego foi correndo para o mato'
$\emptyset$-imanhy i-mymy ina ha-i-pe
3.I-zangar-se 3.II-filho POS 3.II-barriga-LOC
'O filho dela zangou-se (sentado) dentro da barriga dela'

Paralelamente, observa-se no Guajá a existência de um tipo de SVC assimétrica, atestada também no Guarani-Paraguaio (Velázquez-Castillo, 2004), restrita a apenas 4 verbos na posição V2 (5) que seriam o que restou de uma estrutura de predicado complexo na língua que está desaparecendo devido ao processo de gramaticalização dos verbos V2 em marcas aspectuais, representando um outro tipo de compressão.

(5) jaha a-wata-kwa

eu 1SG.I-caçar-saber

'eu sei caçar'

Neste artigo, descreverei as mudanças diacrônicas ocorridas nas sentenças e predicados complexos do Guajá que resultaram na elaboração e compressão de construções a partir da estrutura subordinada adverbial acima citada e a partir de uma possível SVC.

Para tanto, na seção 1 discorrerei brevemente sobre os conceitos de compressão e elaboração propostos por Lehmann (1989); na seção 2 apresentarei a forma como as orações adverbiais de finalidade/simultaneidade se apresentam em algumas línguas da família, considerando as suas diferenças; em 3 descrevo as análises existentes sobre o papel dessas orações subordinadas no surgimento de SVCs; em 4 explicarei como tal construção foi alterada no Guajá passando por processos tanto de elaboração quanto de 
compressão; na seção 5 apresentarei minha hipótese sobre a possível existência de uma SVC em Guajá para, em seguida, desenvolver minhas considerações finais.

Vale ressaltar que, no que se refere aos dados da língua Guajá, todos eles foram coletados por mim em trabalho de campo e são provenientes de falas espontâneas, com exceção de alguns dados elicitados coletados por meio de sessão de elicitação oral para testar a estrutura serializada descrita na seção 5.

\section{O conceito de elaboração e compressão}

Lehmann (1989) apresenta parâmetros relevantes para a vinculação de orações interlinguisticamente, agrupando-os em pares de características que se relacionam por meio de um continuum. Tais parâmetros são fundamentados em uma teoria funcional de ligação de cláusulas que concebe a formação de sentenças complexas como variando entre os polos daquilo que o autor denomina de "elaboração" e "compressão" das informações lexicais e gramaticais. Esta variação cumpre a função dupla de, por um lado, desdobrar uma proposição em dois ou mais componentes proposicionais e, por outro, combinar duas ou mais proposições em uma única composição.

Lehmann explica que as forças de elaboração e compressão agem da seguinte forma para alterar a vinculação entre orações: a primeira atua no sentido da expandir uma sentença em uma construção mais completamente desenvolvida que contém sua própria predicação com todos os acessórios. A força oposta atua no sentido de condensar uma oração completa num constituinte adverbial ou nominal da oração principal.

Assim, em uma estrutura funcional, a vinculação de orações pode ser vista como representando dois estados de coisas tão fortemente interligados que formam um estado complexo de assuntos (compressão) ou, pelo contrário, um estado de coisas como composto de dois estados (elaboração), sendo o relacionamento entre os dois estados de coisas, em ambos os casos, refletidos pela maneira em que eles são vinculados um ao outro na língua (Lehmann, 1989, p. 217-218).

No que se refere às propriedades relevantes para este estudo, destacamos, entre os processos de compressão por ele descritos: i) o movimento de mudança de uma sentença para uma palavra (nível sintático), ii) a dessentencialização, isto é, a perda

Revista Moara, n. 58, jan-jul 2021 ISSN: 0104-0944 
gradativa das propriedades de uma oração, e iii) a gramaticalização de predicados independentes em operadores gramaticais. Tais parâmetros serão aqui utilizados para analisar os processos de compressão e elaboração do Guajá citados na Introdução.

A figura abaixo, adaptada de Lehmann (1989, p. 220) explicitando apenas os parâmetros relevantes para a discussão em tela, ilustra o continuum entre elaboração e compressão.

Figura 1. Paralelismo entre os continua de ligação entre orações

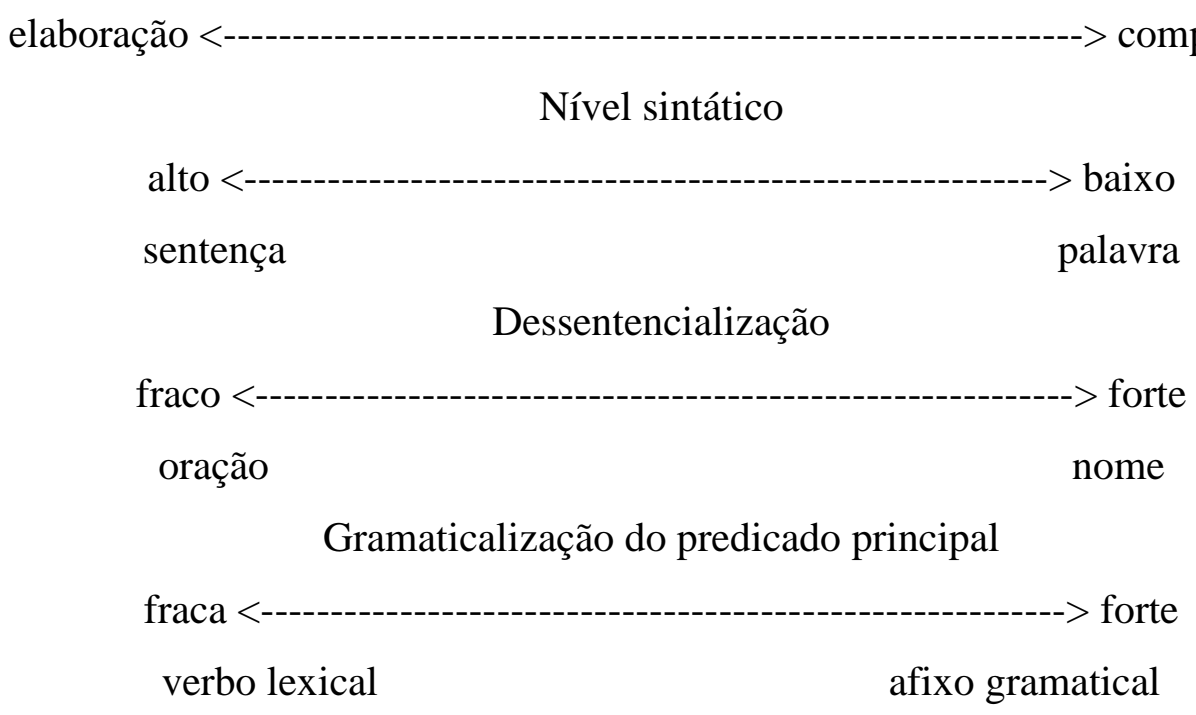

No que diz respeito ao nível sintático, a ideia norteadora é a de que quanto mais baixo for este nível, mais estreita será a integração da oração subordinada à oração principal.

O processo gradativo em que a oração subordinada é expandida ou reduzida, perdendo, na sua redução, as propriedades de uma oração, é denominado de dessentencialização. Assim, gradativamente, os componentes da oração que permitem a referência a um estado de coisas específico são eliminados (actantes, marcas de TAM e polaridade, por exemplo) e, ao mesmo tempo, a oração subordinada adquire cada vez mais propriedades nominais, tanto internamente quanto em sua distribuição. No final deste processo, a oração torna-se um constituinte nominal ou adverbial de uma cláusula matricial.

Já no processo de gramaticalização do verbo principal há uma redução na cláusula principal que transforma verbos lexicais em modais e auxiliares.

Nas próximas seções discutirei os processos de elaboração e compressão identificados na língua Guajá a partir das orações subordinadas adverbiais de 
finalidade/simultaneidade (orações de gerúndio). Antes, porém, descrevo as especificidades desse tipo de construção (seção 2) e apresento as análises prévias de pesquisadores que associaram essas estruturas ao surgimento de SVCs nas línguas da FTG (seção 3).

\section{As orações de "gerúndio"}

De acordo com Cabral e Rodrigues (2005), desde os primeiros estudos sobre as línguas Tupi-Guarani, as orações subordinadas adverbiais que têm seu sujeito correferente ao sujeito da oração principal são conhecidas como orações de gerúndio, enquanto as que têm seu sujeito diferente do sujeito da principal são chamadas de subjuntivas ou conjuntivas (Anchieta 1595, Figueira 1687 [1621], Ruiz de Montoya 1640). ${ }^{2}$ Segundo Seki (2000, p. 313) a tradição de uso deste termo, iniciada por Anchieta, foi “continuada por Rodrigues (1953) em estudos sobre o Tupinambá e por outros estudiosos de línguas Tupi-Guarani (Leite, 1978)". A forma também é referida como construção de converb $^{3}$ (Rose, 2009).

O gerúndio é reconstruído para o Proto-Tupi-Guarani por Jensen (1998), que apresenta o sufixo *-abo, *-ta e *-a como marcador da oração dependente (6) e, de acordo com a hipótese de Cabral e Rodrigues (2005, p. 48), as formas deste sufixo proviriam de antigas nominalizações com o morfema *-áp *-táp que teriam se desenvolvido em um estágio anterior à separação das famílias Aweti e Tupi-Guarani:

$$
\begin{array}{lc}
* a \text {-có } & \text { wi-poracéj-ta } \\
\text { 1.SG.I-ir } & \text { 1SG.III-dançar-GER } \\
\text { 'eu fui para dançar' (Jensen, 1998) }
\end{array}
$$

Essa construção é encontrada em diversas línguas da FTG, como Tupinambá (Rodrigues, 1953), Kamaiurá (Seki, 2000), Tapirapé (Praça, 2007), Assuriní do Tocantins (Cabral e Rodrigues, 2005), Tembé (Duarte, 2001), entre outras, caracterizando-se por apresentar um morfema subordinador associado ao verbo, que expressa tanto a semântica adverbial temporal de simultaneidade e/ou sequências de

\footnotetext{
${ }^{2}$ Esses autores identificam as funções do gerúndio Tupi-Guarani com as do gerúndio e do supino da língua latina.

${ }^{3}$ Converbs formam, assim como SVCs, um predicado único, porém um dos verbos leva uma marca de dependência (Shibatani 2009).
}

Revista Moara, n. 58, jan-jul 2021 ISSN: 0104-0944 
eventos, quanto a semântica de finalidade. Outra característica importante deste tipo de construção é a de que o morfema subordinador está relacionado a um sistema de switchreference que marca sempre mesmo sujeito em sequências de predicados.

Os exemplos a seguir do Tupinambá ilustram as características formais e semânticas desta construção. A indexação de pessoa é específica de orações dependentes e nominalizações, diferindo da marcação de pessoas em orações independentes pelas seguintes características: no caso dos verbos subordinados transitivos, pelo uso exclusivo de uma série que expressa argumento interno do núcleo do predicado (Série II) (7), ou pela prefixação de uma marca de adjacência expressa por meio dos alomorfes r- e $\varnothing$-(glosados como LK, linker $)^{4}$ entre a raiz verbal e seu argumento interno nominal (8); no caso dos verbos subordinados intransitivos, pela série que marca sujeito correferencial (Série III) (9).

$$
\text { o-i-pysyk i-juká-(a)bo }
$$

3.I-3.II-agarrar 3.II-matar-GER

'agarrou-o e matou-o' (Navarro, 1998, p. 179, minha glosa)

$$
\begin{array}{ll}
\text { o-úr kunimí } & \text { Ø-kuáp-a } \\
\text { 3.I-vir criança } & \text { LK-encontrar-GER }
\end{array}
$$

'ele veio para encontrar a criança' (Jensen, 1990, p. 124, minha glosa)

$$
\begin{array}{ll}
\text { a-je?én } & \text { wi-só-bo } \\
\text { 1SG.I-falar } & \text { 1.CORR-ir-GER }
\end{array}
$$

'eu falo enquanto vou' (Anchieta 1595, p. 29v, apud Cabral e Rodrigues, 2005, p. 49, minha glosa)

Em Guajá (Magalhães, 2007), os verbos das orações subordinadas adverbiais associados ao marcador de gerúndio expressam finalidade (10) ou simultaneidade temporal com relação ao evento da oração principal (11) e (12).

(10)

$$
\begin{array}{ll}
\text { jaha } & \text { a-me.me'ẽ } \\
\text { eu } & \text { 1sG.I-RED.olhar }
\end{array}
$$

xí

IMPERF

$$
\text { h-aka }=\mathbf{p a}
$$

$$
\text { 3.II-procurar }=\text { GER }
$$

\footnotetext{
${ }^{4} \mathrm{O}$ morfema ao qual me refiro pelo nome de marca de adjacência/linker (LK) é conhecido amplamente na literatura Tupi-Guarani como prefixo relacional. A opção por não utilizar aqui esta nomenclatura justifica-se pelo fato de ela estar associada a um paradigma formado por prefixos que teriam a função de marcar a contiguidade ou não-contiguidade estrutural (i.e., adjacência dentro de um mesmo sintagma vs. não-adjacência ou separação em sintagmas diferentes) entre um "determinante e o termo por ele determinado" (Rodrigues, 1996). Por entender que o referido prefixo tem função exclusiva de marcar a adjacência entre argumento interno de qualquer tipo de sintagma e seu núcleo, interpretando o que Rodrigues denomina de prefixo relacional de não-contiguidade como prefixo de $3^{\mathrm{a}}$ pessoa, adoto esta outra nomenclatura.
}

Revista Moara, n. 58, jan-jul 2021 ISSN: 0104-0944 
‘eu fiquei olhando para procurá-lo’ (Magalhães, 2007, p. 267)

$\begin{array}{llll}\text { Awa- } \varnothing & \varnothing \text {-irara } & \text { tyrymỹ } & \text { r-ixak-a } \\ \text { homem-RFR } & \text { 3.I-alegrar.se } & \text { farinha } & \text { LK-ver-GER }\end{array}$

'o homem alegrou-se ao ver a farinha' (Magalhães, 2007, p. 267)

$$
\begin{array}{lll}
\varnothing \text {-aho } & \text { takỹn-a } & \text { wewe }=\text { pa } \\
\text { 3.I-ir } & \text { tucano-RFR } & \text { voar }=\text { GER }
\end{array}
$$

'o tucano foi embora voando' (Magalhães, 2007, p. 267)

As orações envolvidas na construção compartilham o mesmo sujeito e TAM, e os verbos transitivos da oração subordinada expressam seu argumento interno pronominal por meio da Série II (10) ou, caso o argumento interno seja um SN, por meio da sua associação com o núcleo verbal mediada por um prefixo de adjacência (LK) (11). O Guajá, diferentemente das línguas supracitadas, perdeu a Série III de marcadores correferenciais que acompanhava os verbos subordinados intransitivos desta construção, o que resultou numa forma verbal dependente nua de prefixos pessoais (12).

O subordinador que marca o modo gerúndio é o sufixo -á, em temas terminados em consoante $\mathrm{k}$ (como em 11), e os pós-clíticos =pa =ma, em temas terminados em vogal oral ou nasal, respectivamente (como em 10 e 12).

Diferentemente de outras línguas da família, no Guajá as sentenças que denotam eventos em sequência não são marcadas pelo sufixo subordinador de gerúndio. Nesses casos, as raízes verbais recebem marcadores pessoais da Série I, exclusiva de verbos em orações independentes, como ilustrado a seguir, configurando uma sentença formada pela justaposição de dois predicados simples:

$\begin{array}{llll}a \text {-jka } & \text { xahu-a } & \text { a-mike'ẽ } & k a \text { 'a-pe } \\ \text { 1SG.I-matar } & \text { porcão-RFR } & \text { 1SG.I -moquear } & \text { mato-LOC } \\ \text { 'Matei o porcão (e) o moqueei no mato.' } & \end{array}$

Uma vez esclarecidas as características semânticas e formais das construções de gerúndio, explicarei, na próxima seção, como a compressão dessas estruturas está diretamente relacionada ao surgimento de Construções Verbais Seriais (SVC) em línguas Tupi-Guarani. Em seguida, na seção 4, apresentarei minha análise de como o Guajá difere dessas línguas no que se refere aos processos de elaboração e compressão identificados a partir dessas orações subordinadas adverbiais. 


\section{O surgimento de SVCs a partir do gerúndio}

O termo serial verb construction (em português, construção verbal serial) foi cunhado por Balmer e Grant (1929), mas o fenômeno ao qual ele se refere foi identificado pela primeira vez na língua Akan por Christaller (1875), e definido posteriormente por Westermann $(1907 ; 1930)$ para a língua Ewe. O termo foi gradativamente sendo estendido para cobrir fenômenos similares ao identificado na língua Akan e foram Foley e Olson (1985) que apresentaram o primeiro estudo multilinguístico com argumentações consistentes defendendo uma análise das construções seriais de verbos como monoclausais. Aikhenvald e Dixon (2006) num volume organizado por ambos com o objetivo de definir SVCs interlinguisticamente, em perspectiva tipológica, apresentam uma construção verbal em série (SVC) como:

(...) uma sequência de verbos que atuam juntos como um único predicado, sem qualquer marcador aberto de coordenação, subordinação ou dependência sintática de qualquer outro tipo. Construções verbais em série descrevem o que é conceituado como um único evento. Elas são monoclausais; suas propriedades entonacionais são as mesmas de uma oração monoverbal, e elas têm apenas um tempo, aspecto e valor de polaridade. As SVCs também podem compartilhar argumentos centrais e outros. Cada componente de uma SVC deve ser capaz de ocorrer por conta própria. Dentro de uma SVC, os verbos individuais podem ter valores de transitividade iguais ou diferentes. ${ }^{5}$ (AIKHENVALD, 2006, p.1)

Segundo a autora, esta definição consolidaria um consenso terminológico entre diversos trabalhos que discutem esse tipo de estrutura em línguas de tipologias variadas (cf. Foley e Olson, 1985; Givón, 1991; Durie, 1997; Crowley, 1987; Zwicky, 1990; Noonan, 1985; e também Andrews e Manning, 1999).

\footnotetext{
${ }^{5}$ No original: a serial verb construction (SVC) is a sequence of verbs which act together as a single predicate, without any overt marker of coordination, subordination, or syntactic dependency of any other sort.2 Serial verb constructions describe what is conceptualized as a single event. They are monoclausal; their intonational properties are the same as those of a monoverbal clause, and they have just one tense, aspect, and polarity value. SVCs may also share core and other arguments. Each component of an SVC must be able to occur on its own. Within an SVC, the individual verbs may have same, or different, transitivity values.
}

Revista Moara, n. 58, jan-jul 2021 ISSN: 0104-0944 
Aikhenvald (2006) apresenta, assim, uma definição de SVCs que cobre uma ampla variedade de significados e funções e pode variar bastante, conforme a língua, consistindo em várias palavras fonológicas e gramaticais, ou formando uma só palavra; tendo componentes que podem estar sempre contíguos ou ser interrompidos por outros constituintes; podendo algumas categorias verbais ser marcadas em cada verbo da série ou apenas uma vez por construção; havendo a possibilidade de os componentes de uma construção em série compartilharem o sujeito da construção, ou compartilhar outro argumento, como o objeto. ${ }^{6}$

Além disso, as SVCs podem ser classificadas como simétricas ou assimétricas (Aikhenvald, 2006, p. 3) conforme o tipo de composição atestada entre os verbos da série: construções simétricas consistem em dois ou mais verbos, cada um pertencente a uma classe irrestrita semântica e gramaticalmente; construções assimétricas incluem um verbo pertencente a uma classe semântica ou gramaticalmente restrita.

No que se refere às línguas Tupi-Guarani, há, na literatura, registro de construções verbais seriais identificadas em algumas delas.

Jensen (1990, p. 124-125) descreve como "serial verbs" as construções de gerúndio das línguas Tupi-Guarani. Segundo a autora, nessas construções, os dois verbos são percebidos pelos falantes como aspectos de uma única ação. Os dois exemplos do Tupinambá a seguir ilustram a referida construção, interpretada por Jensen como SVC:

o-úr i-kwáp-a

3.I-vir 3.II-conhecer-SER

'ele veio para conhecê-lo(a)’ (Jensen, 1990, p. 124, minha glosa)

o-úr kunumi $\quad$ Ø-kwáp-a
3.I-vir criança $\quad$ LK-conhecer-SER
'ele veio para conhecer a criança' (Jensen, 1990, p. 124, minha glosa)

\footnotetext{
${ }^{6}$ Já Haspelmath (2016), ao argumentar que o conceito de SVC não foi delimitado claramente, tendo sido formulado em termos muito amplos, propõe uma definição mais estreita para o fenômeno, excluindo características presentes em definições anteriores, em particular as que dizem respeito a combinações não composicionais, combinações com um verbo que não ocorre independentemente, combinações com palavras que expressam propriedade (como por exemplo, verbos estativos) e combinações entre verbos que estabelecem uma relação de argumento e predicado, isto é, construções com semântica de complementação.
}

Revista Moara, n. 58, jan-jul 2021 ISSN: 0104-0944 
No entanto, a estrutura descrita por Jensen não se qualifica de fato como uma construção verbal serial, conforme foi demonstrado por Seki (2000, p. 331-314), uma vez que se trata de construção composta por dois predicados, um dos quais é marcado como um verbo dependente justamente pelo sufixo que Jensen denomina de marcador serial (SER) e pela série II de marcadores pessoais, típica de estruturas menos finitas. Assim, a estrutura descrita por Jensen (1990) trata-se de uma oração subordinada adverbial (uma construção de gerúndio), conforme já explicado na seção 2.

Velázquez-Castillo (2004), em sua análise do Guarani paraguaio, identifica três tipos de construções que, segundo ela, seriam "uma reminiscência do fenômeno conhecido como 'serialização de verbos"” (Velázquez-Castillo, 2004, p. 187):

$$
\begin{array}{ll}
\text { o-karu-(ta) } & \text { o-hó-vo } \\
\text { 3.I-eat(-FUT) } & \text { 3.I-go-SER }
\end{array}
$$

'S/he will eat as she goes'. (Velázquez-Castillo, 2004, p. 187, minha glosa)

$$
\begin{array}{ll}
\text { o-pu'ã-(ta) } & \text { o-guata } \\
\text { 3.I-get.up(-FUT) } & \text { 3.I-walk }
\end{array}
$$

'He gets up and walks'. (Velázquez-Castillo, 2004, p. 188, minha glosa)

$$
\begin{array}{ll}
\text { o-guapy } & \text { jeko(-ta) } \\
\text { 3.I-sit } & \text { lean(-FUT) }
\end{array}
$$

'He sits leaning back'. (Velázquez-Castillo, 2004, p. 188, minha glosa)

Segundo a autora, em (16), o padrão o-V1 o-V2-vo é identificado quando há dois predicados, cada um carregando seu próprio prefixo pessoal, com morfologia de Tempo / Aspecto / Modalidade (TAM) - ilustrada pelo morfema -ta (FUT) - e negação em V1, além de um sufixo -vo em V2, havendo, entre os dois predicados interpretação temporal de simultaneidade ou sequencial. Em (17), o padrão o-V1 o-V2 identifica uma serialização de movimento em que V1 é um verbo de movimento que conduz ao evento expresso por V2, ambos compartilhando o mesmo sujeito (nas palavras da autora, o mesmo "ator"). A sequência não é marcada com -vo e deve ser interpretada sequencialmente. Cada verbo é individualmente marcado para pessoa e a morfologia TAM está principalmente em V1, embora ocasionalmente V2 carregue sua própria morfologia aspectual. Em (18), o padrão o-V1-V2, envolve dois predicados ativos 
consecutivos, um sujeito marcado em V1 $(o-)$ e um único conjunto de morfologia TAM seguindo V2.

No que se refere à construção o-V1 o-V2-vo, em que -vo é glosado pela autora como SER (serializador), é possível identificar que o sufixo é cognato do sufixo -ábo de "gerúndio" reconstruído para o proto-Tupi-Guarani, com a diferença de que, no Guarani paraguaio, ele integra uma estrutura que não pode ser mais analisada tão claramente como subordinada, uma vez que o V2 ao qual ele se anexa não recebe marca de pessoa específica de predicado subordinado nem pode ser negado independentemente. Velázquez-Castillo (2004) analisa a construção como uma única cláusula, sendo V1 o verbo nuclear, o que propicia, a meu ver, uma análise mais próxima da definição de coverbo (converb) ${ }^{7}$. Já as construções o-V1 o-V2 e o-V1-V2 se encaixam nas definições mais abrangentes de SVCs por não apresentarem qualquer marca morfológica de coordenação, subordinação ou dependência sintática, por compartilharem o mesmo sujeito e morfologia de TAM e designarem um único macroevento (nas palavras da autora, o evento unitário é uma questão de grau, que varia semântica e formalmente a depender do tipo de serialização). Estas possivelmente têm sua origem a partir da perda da estrutura subordinada adverbial marcada pelo sufixo -vo.

Rose (2009) apresenta SVCs em Emerillón e mostra evidências de sua origem a partir das referidas orações de gerúndio (as quais denomina de "converb construction") que perderam as marcas de oração dependente - a série não-ativa (ou Série II) de prefixos pessoais e o sufixo subordinador - e passaram a funcionar como construção serializada. Apesar de os verbos que compõem a estrutura descrita por Rose (2009) ocorrerem cada um com seu marcador de pessoa e permitirem a inserção de constituintes entre os verbos da série (19), a interpretação de que realmente se trata de uma construção de verbos seriais se sustenta pelas seguintes características: os verbos da sentença formam um predicado único sem qualquer marca morfológica de dependência, compartilham sujeito e objeto (19), compartilham morfologia TAM (20) e polaridade (21).

$$
\text { o-kuar zadupa o-kirig }
$$

\footnotetext{
${ }^{7}$ Bril (2004) define converbs como formas verbais não finitas cuja função principal é a de marcar uma subordinação adverbial, modificando verbos, orações ou sentenças. Rose (2009) explica que a diferença básica entre converbos e verbos seriais parece ser a presença de um marcador morfológico de dependência naquele.
}

Revista Moara, n. 58, jan-jul 2021 ISSN: 0104-0944 
3.I-find genipa 3.I-grate

'she found genipa and grated it' (Rose, 2009, p. 653)

(20)

a-nan-tar a-ze-mim

1.SG.I-run-FUT 1.SG.I-REFL-hide

'I am going to run and hide myself' (Rose, 2009, p. 652)

d-a-nan-i a-ze-mim

NEG-1.SG.I-run-NEG 1.SG.I-REFL-hide

'I did not run and hide myself' (Rose, 2009, p. 652)

Kakumasu (1986, p. 386) apresenta construções com o que denomina 'auxiliares aspectuais' em Ka'apór que podem ser analisadas como SVCs assimétricas com verbos posicionais ocupando a posição de V2. Tais estruturas apresentam V1 pertencentes a classes abertas e a posição V2 é restrita a apenas quatro verbos que denotam posição e que, apesar de levarem marcador pessoal e permitirem a inserção de constituintes entre os verbos da série, aparentemente encaixam-se nas demais características das construções seriais: atuam como verbos nucleares em orações independentes, parecem, pela descrição, compor um predicado monoclausal, compartilham TAM e sujeito e objeto com o verbo nuclear. No entanto, não há dados suficientes para atestar se há compartilhamento de polaridade. São exemplos dessa construção do Ka'apór:

$$
\begin{array}{llllll}
\text { ihe } & \text { riki } & \text { wewe } & \text { katu } & \text { a-jur } & a-x o \\
\text { I } & \text { EMPH } & \text { slowly } & \text { good } & \text { 1SG.I-come } & \text { 1SG.I-move }
\end{array}
$$

'I was coming very slowly.' (Kakumasu, 1986, p. 386)

$\begin{array}{lllll}a m e^{\prime} \tilde{e} & p e & \text { ihe } & \text { a-nino } & a-j u \\ \text { that.one } & \text { in } & \text { I } & \text { 1SG.I-lie.down } & \text { 1SG.I-lie }\end{array}$

'I was lying down in that (hammock).' (Kakumasu, 1986, p. 386)

As aparente SVCs do Ka'apór provavelmente têm a mesma origem das encontradas no Guarani paraguaio e no Emerillón: a perda do sufixo de gerúndio nas orações subordinadas adverbiais e a perda da marcação de pessoa típica de orações menos finitas (observe que os V2 recebem as marcas da Série I, a mesma dos verbos que ocorrem em orações independentes). Só que, neste caso, essa estrutura está restrita aos quatro verbos que denotam posição na língua.

Revista Moara, n. 58, jan-jul 2021 ISSN: 0104-0944 
A partir dessas descrições, fica evidente a relação entre a perda das construções de gerúndios e o surgimento de SVCs em algumas línguas da FTG, conforme defende Rose (2009) para o Emerillón.

Analisando essas transformações do ponto de vista da ligação entre as orações, podemos concluir que temos, na origem, uma sentença complexa formada por oração principal e oração subordinada adverbial, que expressa dois estados de coisas (proposições), um subordinado ao outro, com o compartilhamento de pelo menos um actante, o sujeito. Com o estreitamento da vinculação, as duas proposições passam a ficar tão fortemente interligadas que formam um estado complexo de assuntos, evidenciando um movimento de compressão (Lehmann, 1989) em que a sentença, localizada num dos pólos do continuиm, vai gradativamente perdendo as propriedades biclausais (a perda do sufixo subordinador, das marcas independentes de TAM e polaridade) num evidente processo de dessentencialização ${ }^{8}$, tornando-se um predicado complexo. As SVCs estariam, segundo o autor, num estágio intermediário entre os dois extremos desse gradiente de ligação entre orações, isto é, entre a elaboração máxima (sentença) e a compressão máxima (palavra), sendo esta última representada por verbos nominalizados ou gramaticalizados.

Na próxima seção explicito como o Guajá difere dessas línguas no que se refere aos desdobramentos diacrônicos a partir das orações de gerúndio.

\section{Elaboração e compressão de sentenças no Guajá a partir do gerúndio}

Nesta seção trataremos dos processos de mudança ocorridos no Guajá a partir das construções de gerúndio que atestam por um lado o afrouxamento na ligação entre as orações - elaboração -, e, por outro, o estreitamento da relação entre os verbos compressão.

\subsection{Elaboração: de orações subordinadas a independentes}

\footnotetext{
${ }^{8}$ A dessentencialização é caracterizada por Lehmann (1989) como a perda da força ilocucionária, bem como o compartilhamento das marcas de TAM e dos actantes e circunstantes.
}

Revista Moara, n. 58, jan-jul 2021 ISSN: 0104-0944 
Conforme citado na seção 2, o Guajá apresenta construções de gerúndio por meio da associação dos morfemas $-a \sim=p a \sim=m a$ ao verbo núcleo da oração dependente e da marcação de pessoa por meio da Série II (no caso dos verbos transitivos) ou da não marcação de pessoa (nos casos dos verbos intransitivos). Porém, tais orações expressam apenas finalidade e/ou simultaneidade. Para expressar sequência de eventos, o Guajá perdeu o sufixo subordinador e a referida marcação de pessoa e, nesses casos, todas as raízes verbais que denotam os eventos em sequências recebem índices pessoais da Série I, exclusiva de verbos em orações independentes. Os exemplos abaixo mostram o contraste entre uma oração adverbial de finalidade/simultaneidade (gerúndio) (24), e as sentenças que expressam eventos em sequência (25).

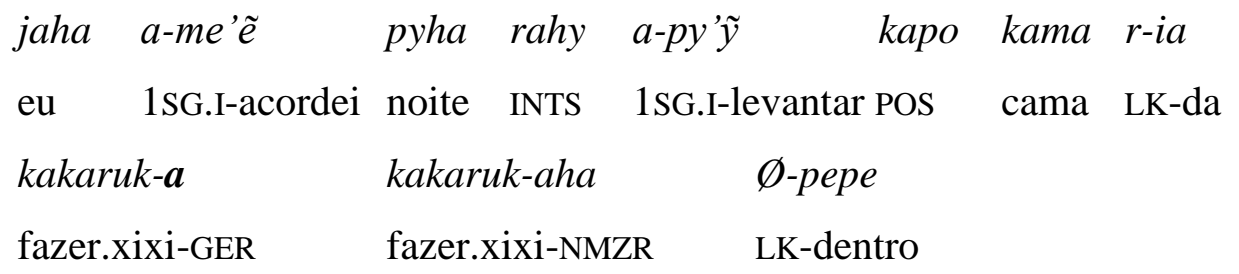

'eu acordei tarde da noite e levantei da cama para fazer xixi no banheiro'

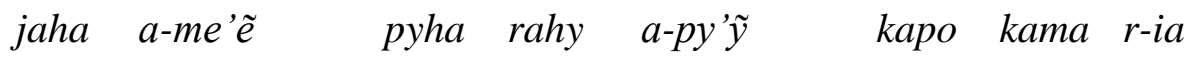
eu 1SG.I-acordei noite INTS 1SG.I-levantar POS cama LK-da

a-kakaru kakaruk-aha $\quad$-pepe

1SG.I-fazer.xixi fazer.xixi-NMZR LK-dentro

'eu acordei tarde da noite, levantei da cama e fiz xixi no banheiro'

Em (24), os dois primeiros verbos, me'ẽ 'acordar' e py' $\tilde{y}$ 'levantar' compõem um sequência de eventos e são marcados com o índice pessoal da Série I, sem qualquer sufixo subordinador associado a eles, enquanto o verbo kakaru 'fazer.xixi', que compõe uma oração subordinada adverbial final, ocorre com o sufixo subordinador - $a$ e, por ser um verbo intransitivo, ocorre sem qualquer marca de pessoa. Já em (25) a mesma situação se repete com os dois primeiros verbos que compõem orações denotando sequência de eventos, e o terceiro verbo, desta vez denotando um evento sequencial, é marcado como os demais, isto é, apenas com o prefixo pessoal da Série I, configurando uma sentença com três predicados independentes.

Numa análise superficial, poder-se-ia supor que a perda do marcador de dependência nas orações com semântica de sequência de eventos ilustrada em (25) 
resultou numa SVC do tipo o-V1 o-V2 descrito por Velázquez-Castillo (2004), em sua análise do Guarani paraguaio, ou do tipo identificado por Rose (2009) para o Emerillón.

No entanto, uma análise mais aprofundada nos leva a concluir que a perda da marca de dependência no Guajá resultou não em sentenças monoclausais, mas em sentenças biclausais ou multiclausais coordenadas entre si, por uma série de motivos.

Primeiramente, há pausas internas entre os verbos da sequência e nenhuma evidência morfofonológica ou sintática de que eles atuem como uma proposição mais conectada de modo a constituir um predicado único:

$\begin{array}{llclll}a \text {-jaho } & x i & h a=r \text {-ipa-pe } & a \text {-wata } & \text { ta } & \text { aha } \\ \text { 1SG.I-ir } & \text { COND } & \text { 1SG.II-LK-casa-LOC } & \text { 1SG.I-caçar } & \text { PROJ } & \text { CTF } \\ \text { ka'a-pe } & a \text {-jka } & \text { wari-a } & a-' u & m a & \\ \text { mata-LOC } & \text { 1.SG.I-matar } & \text { guariba-RFR } & \text { 1SG.I-comer } & \text { TOT } & \end{array}$

'se eu for para casa eu vou caçar na mata, matar guariba e comer ele

todo'

Em segundo lugar, a marca de TAM pode ocorrer associada apenas ao primeiro verbo da sequência, como em (26) acima em que a partícula de aspecto projetivo ta (PROJ) ocorre associada ao verbo wata 'caçar' e tem como escopo também os demais verbos que o seguem, mas é comum encontrarmos dados em que cada verbo recebe as marcas de TAM independentemente (27):

$$
\begin{aligned}
& \text { jaha a-jaho ta ha=r-ipa-pe a-kere ta } \\
& \text { eu 1SG.I-ir PROJ 1SG.II-LK-casa-LOC 1SG.I-dormir PROJ } \\
& h a=\emptyset-k a h a-p e \\
& \text { 1SG.II=LK-rede-LOC } \\
& \text { 'eu vou para casa e vou dormir na minha rede' }
\end{aligned}
$$

A polaridade é sempre marcada independentemente em cada verbo da sentença e tem como escopo apenas o verbo com o qual os morfemas descontínuos $n=\ldots-i$ ocorrem:

\begin{tabular}{lllll} 
(28) jaha $\quad$-jaho & ta & \multicolumn{2}{c}{ ha=r-ipa-pe } & \\
eu 1 SG.I-ir & PROJ & 1SG.II-LK-casa-LOC & \\
$n=a-k e r e$ & tar-i-hi $\quad$ kama & r-ehe & jaha \\
NEG=1SG.I-dormir & PROJ-NEG-INTS cama & LK-sobre & eu \\
'eu vou para casa e não vou dormir na cama' & &
\end{tabular}

Revista Moara, n. 58, jan-jul 2021 ISSN: 0104-0944 
Além disso, é possível que verbos em sequência compartilhem o mesmo sujeito e objeto, como em (26), mas não necessariamente. Em (29), cada verbo possui seu próprio sujeito e seu próprio objeto ${ }^{9}$ :

$\begin{array}{lllll}\text { Tatuxa'a- } \varnothing & x a h u-a & \emptyset \text {-ika } & \text { ta } & x i \\ \text { Tatuxa'a-RFR } & \text { porcão-RFR } & \text { 3.I-matar } & \text { PROJ } & \text { IMPERF } \\ \text { Warixa'akuruhu- } a & \emptyset \text {-xa } & t a \quad x i & & \text { kamixa- } \varnothing \\ \text { Warixa'akuruhu-RFR } & \text { 3.I-ver } & \text { PROJ } & \text { IMPERF } & \text { jabuti-RFR }\end{array}$

'Tatuxa'a queria matar porcão e Warixa'a queria ver jabuti'

Por fim, constituintes como SNs e SPs podem figurar entre os verbos da sequência:

$$
\begin{aligned}
& \text { jaha a-jaho ta ha=r-ipa-pe mukuri-a } \\
& \text { eu 1SG.I-ir PROJ 1sG.II-LK-casa-LOC mukuri-RFR } \\
& \text { a-’u ta ha=r-ipa-pe } \\
& \text { 1SG.I-comer PROJ 1SG.II-LK-casa-LOC } \\
& \text { 'eu vou voltar para casa e vou comer bacuri' }
\end{aligned}
$$

Assim, diferentemente do que ocorre em Guarani Paraguaio e Emerillón, em que as orações de gerúndio são a origem de processo de compressão na ligação entre orações, gerando SVCs, as sentenças com predicados verbais que expressam sequência de eventos do Guajá, por não constituírem um único predicado complexo, mas uma sequência assindética de predicados independentes, evidenciam o processo contrário, de elaboração, em que a ligação entre oração principal e subordinada tornou-se mais frouxa, dando lugar a orações coordenadas (parataxe), que expressam eventos distintos, não são marcadas por qualquer material morfofonológico e possuem marcas de actantes, TAM e polaridade independentes.

Por fim, é importante deixar claro que este processo de mudança diacrônica de sentença complexa (subordinada) para predicados simples independentes ainda está em processo, pois é comum encontrar dados que atestam uma ligação mais estreita entre as sentenças coordenadas que compartilham o mesmo sujeito do que entre as que não o

\footnotetext{
${ }^{9}$ Vale ressaltar que as sentenças com sujeitos distintos não têm sua origem nas construções de gerúndio, uma vez que estas são caracterizadas pela ocorrência do mesmo sujeito. No entanto, sincronicamente, não há diferença significativa entre as sentenças que expressam sequência de eventos, sejam elas formada por verbos que compartilham o mesmo sujeito ou que têm sujeitos distintos, a não ser o fato de que aquelas podem compartilhar com a oração principal as marcas de TAM.
}

Revista Moara, n. 58, jan-jul 2021 ISSN: 0104-0944 
compartilham. Naquelas, justamente as oriundas das construções de gerúndios, há registros de dados com compartilhamento de TAM (26), o que não é atestado nessas.

O exemplo adicional abaixo ilustra essa característica. Numa mesma sentença, encontramos a expressão de uma sequência de eventos, representada pelos três primeiros verbos, sem marcação de dependência entre cada um, e, ao fim, o último verbo, subordinado expressando finalidade, marcada pelo subordinador $=m a$. Todos os verbos da sentença, independente ou dependente, compartilham o marcador de aspecto projetivo $t a$ associado ao primeiro verbo:

$\begin{array}{lllll}\begin{array}{l}a \text {-jaho } \\ \text { 1SG.I-ir }\end{array} & \text { PROJ } & \text { mata-Le } & a \text {-jka } & \text { tapi'ir-a } \\ \text { a-kere } & i k a-h a & \text { 1SG.I-matar } & \text { anta-RFR } \\ \text { 1SG.I-dormir } & \text { matar-NMZR } & \text { LK-sobre mata-LOC } & \text { CAUS-secar = FIN } \\ \text { 'eu vou para a mata, vou matar anta e vou dormir na caçada para } \\ \text { moqueá-la' }\end{array}$

\subsection{Compressão: de orações subordinadas a predicados monoclausais complexos}

Além do processo de elaboração descrito acima, as construções de gerúndio do Guajá são também a fonte de um processo de compressão a partir da gramaticalização de verbos que denotam movimento e posição. Tais verbos, ao figurar como núcleo de orações adverbiais de finalidade/simultaneidade, acabaram se tornando partículas especializadas em expressar direção e posição (Magalhães, 2019).

Assim, por exemplo, verbos que ocorrem independentemente na língua como aho 'ir' e $u$ 'vir' se gramaticalizaram nas partículas direcionais centrífuga aha 'indo' e centrípeta awa 'vindo', respectivamente. Já a partícula posicional $i k a$ 'em pé, em movimento' é proveniente do verbo iku 'estar em pé, em movimento' e a partícula posicional kata 'em movimento pendular' tem sua origem no verbo kato 'balançar'. 10

Sincronicamente as partículas direcionais e posicionais "são palavras independentes, invariáveis, de conteúdo gramatical e de posição obrigatoriamente

\footnotetext{
${ }^{10}$ Para mais detalhes sobre o processo de gramaticalização de verbos em partículas direcionais e posicionais no Guajá, ver Magalhães (2019).
}

Revista Moara, n. 58, jan-jul 2021 ISSN: 0104-0944 
posterior ao núcleo do predicado, podendo, no entanto, ser precedidas por outras palavras." (Magalhães, 2019, p. 900)

Nesse tipo de construção, a combinação do verbo lexical com a partícula é interpretada como um só evento, uma vez que a partícula expressa a noção gramatical de direção ou posição do evento denotado pelo verbo. Os exemplos a seguir ilustram sentenças com a partícula direcional centrífuga aha 'indo' e com a partícula posicional kata 'em movimento pendular':

$$
\text { Ø-wyhy tapi'i aha are=r-ixak- } a
$$

3.I-correr anta CTF 1.PL.II-LK-ver-FIN

'a anta correu (indo) ao nos ver' (Magalhães, 2007, p. 101)

$$
\varnothing \text {-wata kata }
$$

3.i-andar POS

'ele anda mancando (realizando movimento de pêndulo)!' (Magalhães, 2019, p. 903)

A origem diacrônica destas partículas a partir das construções de gerúndio pode ser atestada pela sua forma fonética, relacionada ao sufixo de gerúndio *áko, reconstruído para o Proto-Aweti-Tupi-Guarani (Cabral e Rodrigues, 2005), que gerou partículas terminadas em apo: kapo 'partícula direcional elativa' e tapo 'partícula posicional em pé'. A redução da sequência -áßo para - $a$ em diversas línguas TupiGuarani (Cabral e Rodrigues, 2005), incluindo o Guajá, justifica que a grande maioria dessas partículas termine com a vogal $a$, que é a forma mais antiga do sufixo de finalidade/simultaneidade ainda hoje existente na língua.

Além disso, outras línguas da família, como o Tapirapé, atestariam o estágio intermediário de gramaticalização desses verbos a partir das construções de gerúndio (Magalhães 2019).

Conforme Praça (2007, p. 207), alguns verbos de movimento, como a 'ir', quando núcleo de oração subordinada no 'modo gerúndio', expressam a direcionalidade da ação evidenciada pelo verbo principal, como nos exemplo a seguir:

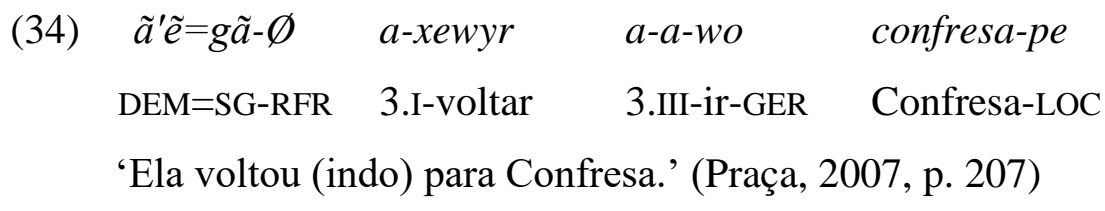


No Tapirapé, um verbo lexical de movimento recebe morfema subordinador expressando simultaneidade das ações expressas pelos verbos principal e subordinado. Sendo o verbo subordinado um verbo que expressa direção (ir, vir e voltar), ele passa a indicar a direção do movimento expresso pelo verbo principal. No Guajá, "esse verbo no gerúndio se gramaticalizou em partículas direcionais, uma vez que não é mais possível analisar a forma gramaticalizada como uma associação da raiz verbal com o sufixo" (Magalhães, 2019, p. 907). O mesmo processo teria ocorrido também com as partículas posicionais, quando a gramaticalização ocorreu a partir de verbos que expressam posição.

Dessa forma, a gramaticalização de verbos posicionais e de movimento, que ocorriam como núcleo de orações de gerúndio, em partículas posicionais e direcionais, condensando a construção subordinada em um único predicado, evidencia um outro processo de compressão na ligação entre as orações de uma sentença, transformando uma construção biclausal em monoclausal; uma sentença complexa numa sentença simples.

A gramaticalização de verbos em partículas acima descrita, quando comparada com a formação de SVCs descrita na seção anterior, ilustra o avanço do processo de compressão, uma vez que reflete um estreitamento ainda maior na vinculação entre os verbos que compunham as duas orações: as partículas, por serem elementos de conteúdo exclusivamente gramatical que só ocorrem associadas aos verbos (diferente dos verbos em série, que podem ocorrer isoladamente na língua), figuram como um componente gramatical de uma sentença simples e não um predicado complexo.

\section{Sobre uma possível análise de SVCs no Guajá}

Se, por um lado, as construções de gerúndio do Guajá não resultaram em SVCs, há um outro tipo de predicado sincronicamente complexo na língua que pode ser analisado como tal, uma vez que determinadas raízes verbais independentes ocorrem como segundo verbo de uma sequência verbal p-V1-V2, sendo p- um prefixo pessoal de verbos independentes:

$a-w a t a-k w a$

1SG.I-andar-saber

Revista Moara, n. 58, jan-jul 2021 ISSN: 0104-0944 
'Eu sei andar.'

Arakari'̃-a

Arakari'ĩ-RFR 3.I-fazer tipóia-RFR ser.perfeito

'Arakari'ĩa faz tipoia perfeitamente'

O exemplo (35) mostra o verbo eventivo kwa 'saber', que também ocorre como verbo lexical independente associado a marcas de pessoas da Série I ( $a-k w a$ 'eu sei'), ocorrendo como segundo verbo de uma construção que envolve sequências verbais em que V1 leva a marca de pessoa e é seguido imediatamente por V2, este sem índice pessoal ou qualquer marca de subordinação ou coordenação.

O exemplo (36) mostra a posição V2 sendo ocupada por um verbo estativo parahỹ 'ser perfeito/certo/bonito/bom', que também ocorre como verbo lexical independente ( $h a=\varnothing$-parahy 'eu sou perfeito/bonito'), sempre associado a marcas de pessoas da Série II, por ser um verbo estativo. No entanto, quando esse verbo integra esse tipo de construção, ocorre sem qualquer índice pessoal ou marca de subordinação.

Além desses, há outros dois verbos até então identificados que podem exercer a mesma função: o verbo eventivo pa 'terminar', e o verbo estativo manahỹ 'ser imperfeito/errado/feio/ruim'.

Tal construção pode ser considerada uma SVC por ter as seguintes propriedades:

a) Cada verbo da construção pode atuar como núcleo de uma oração independente

$a-k w a$

karai

Ø- $\tilde{\imath}-h a$

1SG.I-saber não-indígena LK-falar-NMZR

'eu sei falar a língua dos não-indígenas'

$\emptyset$-pa i-mymy n-imi'ũ- $a$

3SG.I-terminar 3SG.II-criança LK-comida-RFR

'a comida da criança terminou'

$n i=\emptyset-p a r a h \tilde{y}$

nija

2SG.II-ser.perfeito

você

'você é bonito/perfeito'

$\begin{array}{lrl}\text { Ø-manahỹ } & \text { ra'o terẽ } & \emptyset \text {-ma'i-ha } \\ \text { 3SG.II-ser.ruim } & \text { INTS trem } & \text { LK-conversar-NMZR } \\ \text { 'é muito ruim o barulho do trem' }\end{array}$

b) Não há marcador de dependência no verbo não nuclear

Revista Moara, n. 58, jan-jul 2021 ISSN: 0104-0944 
(41)

Junai-a ha-mi'ũ-a u-'u-pa ta manã kwy

Junai-RFR 3SG.II-comida-RFR 3.I-comer-terminar PROJ DIR ali

'Junai vai terminar de comer a comida dele ali'

$\begin{array}{llll}\text { Jurixi-a } & \varnothing \text {-japo } & \text { ha-wy'y-a } & \text { parahy } \\ \text { Jurixi-RFR } & \text { 3.I-fazer } & \text { flecha-RFR } & \text { ser.perfeito } \\ \text { 'Jurixia faz sua flecha perfeitamente' } & \end{array}$

c) A sentença forma um predicado único. Não há pausa entonacional nem pausas internas entre os verbos da sequência. Em termos morfofonológicos, as SVCs com verbos eventivos são contíguas, isto é, os verbos que as compõem não podem ser separados por nenhum constituinte, e formam uma palavra única, com apenas um acento fonológico.

$$
\begin{array}{llll}
\text { Hajkaramykỹ-a } & \text { ha-mi'ũ-a } & \text { u-'u-pa } & \text { ta } \\
\text { Hajkaramykỹ-RFR } & \text { 3SG.II-comida-RFR } & \text { 3.I-comer-terminar } & \text { PROJ }
\end{array}
$$

'Hajkaramykỹa vai terminar de comer a comida dele'

$$
\begin{aligned}
& \emptyset \text {-wata-kwa i-mymyra aja'a } \\
& \text { 3.I-andar-saber } \quad \text { 3.II-filho-RFR ele } \\
& \text { 'o filho dela sabe andar' }
\end{aligned}
$$

Já as SVCs com verbos estativos são não-contíguas, isto é, permitem que um SN ocorra entre seus componentes (45). Mas quando os dois verbos estão contíguos, formam uma só palavra, com apenas um acento fonológico (46).

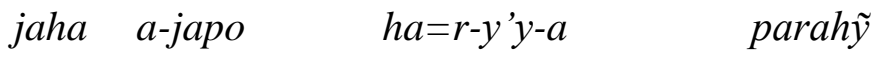

eu 1SG.I-fazer 1SG.II=LK-flecha-NMZR ser.perfeito

'eu faço minha flecha perfeitamente'

$$
\begin{array}{llc}
\text { jaha } & \text { a-japo-parahy } & h a=r-y \text { 'y- } a \\
\text { eu } & \text { 1SG.I-fazer-ser.perfeito } & \text { 1SG.II=LK-flecha-NMZR }
\end{array}
$$

'eu faço minha flecha perfeitamente'

Em termos morfossintáticos, as SVCs formadas por verbo eventivo ou estativo, comportam-se como uma única palavra gramatical, uma vez que levam apenas uma marca de nominalização (47 e 48) e formam um predicado único de oração subordinada, como qualquer verbo independente (49 e 50):
jaha a-maparỹ $\quad h a=n$-imi'ũ
eu 1SG.I-gostar 1SG.II=LK-comida
Ø-'u-pa-ha
LK-comer-terminar-NMZR

Revista Moara, n. 58, jan-jul 2021 ISSN: 0104-0944 
'eu gosto de terminar de comer minha comida'

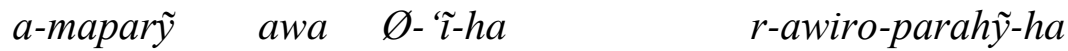

1SG.I-gostar Awa LK-falar-NMZR LK-ler-ser.perfeito-NMZR

'eu gosto de ler direito a língua dos Awá'

a-jrara

ta $h a=\emptyset$-mymy $\varnothing$-wata-kwa

mehe

1SG.I-ser.feliz

PROJ 1SG.II=LK-filho LK-andar-saber

TEMP

'eu vou ficar feliz quando meu filho aprender a andar'

$\begin{array}{lllll}\text { Hajkaramykỹa } & \varnothing \text {-wata } & \text { ta } & \text { aha } & \text { ka'a-pe } \\ \text { Hajkaramykỹ-RFR } & \text { 3.I-caçar } & \text { PROJ } & \text { CTF } & \text { mata-LOC } \\ \text { ha-wy'y } & \varnothing \text {-japo-parahy } & n \tilde{e} & & \\ \text { 3sG.II-flecha } & \text { LK-fazer-ser.perfeito } & \text { CONS }\end{array}$

'Hajkaramykỹa vai caçar na mata depois que fizer direito a flecha dele'

d) Há compartilhamento de TAM e polaridade, pois tanto a partícula de aspecto projetivo quanto a negação descontínua de predicados $n=\ldots-i$ ocorrem apenas uma vez, tendo como escopo ambos os verbos.

$n i=\emptyset-w a t a-k w a$ tar $-i$

ha=Ø-mymyr-a apo ty

$\mathrm{NEG}=3 . \mathrm{I}$-andar-saber PROJ-NEG

1SG.II=LK-filho-RFR DUB EXCL

'meu filho aparentemente não vai apreender a andar (tão cedo)'

Hajkaramykỹ- $a \quad h a=m i ' \tilde{u}-a \quad n=u-$ ' $^{\prime}$-pa tar- $i$

Hajkaramykỹ-RFR 3SG.II=comida-RFR NEG=3.I-comer-terminar PROJNEG

'Hajkaramykỹ não vai terminar de comer toda a comida dele'

$$
\begin{array}{lll}
n=a-j a p o-p a r a h \tilde{y} \text { tar- } i & \text { tapaj-a } & \text { jaha } \\
\text { NEG=1SG.I-fazer-ser.perfeito PROJ-NEG } & \text { tipoia-RFR } & \mathrm{eu} \\
\text { 'eu não vou fazer perfeitamente uma saia' } & &
\end{array}
$$

e) Sujeito e objeto são sempre compartilhados nesse tipo de construção, como é possível atestar em todos os exemplos de (35) a (53).

Assim, por ter todas as propriedades formais necessárias identificadas por Aikhenvald e Dixon (2006) ${ }^{11}$, tais construções do Guajá podem ser consideradas SVCs,

\footnotetext{
${ }^{11}$ A partir da definição mais estreita de Haspelmath (2016) não é possível identificar tais construções como SVCs porque as combinações com palavras que expressam propriedade (como por exemplo, verbos estativos) são excluídas da definição do autor, assim como as combinações entre verbos que estabelecem
}

Revista Moara, n. 58, jan-jul 2021 ISSN: 0104-0944 
mesmo que restrita a apenas 4 verbos. Configuram uma construção assimétrica, com verbos de dois tipos ocupando a posição V2, divergindo também quanto à contiguidade.

Minha hipótese é a de que possivelmente esse tipo de construção foi mais produtiva em fases anteriores, mas, como SVCs assimétricas tendem a se gramaticalizar (Durie,1996), é possível atestarmos sincronicamente apenas esses quatro verbos no Guajá integrando a estrutura. O motivo dessa restrição seria o processo de gramaticalização de outros verbos que figuravam como V2 em partículas aspectuais, o que pode ser evidenciado a partir da comparação do Guajá com outras línguas da família.

É possível demonstrar, por exemplo, que o verbo *mata 'querer/desejar' do Guajá se gramaticalizou como marca de aspecto projetivo a partir de uma estrutura serializada em que ocorria como o segundo verbo, com semântica desiderativa, e, no processo de gramaticalização, perdeu a possibilidade de ocorrer sozinho como núcleo de predicado, adquirindo posição fixa pós-verbal e semântica aspectual projetiva, como no exemplo a seguir:

$$
\begin{array}{ll}
a \text {-wata } & \text { ta } \\
\text { 1SG.I-andar } & \text { PROJ } \\
\text { 'Eu andarei.' } &
\end{array}
$$

A possibilidade de a raiz do verbo lexical 'querer' ocorrer em construções similares às SVCs acima descritas é atestada em outras línguas da FTG. Em Kamaiurá a raiz do verbo lexical potat 'querer/desejar', cognata à mata do Guajá, além de ocorrer como núcleo de oração independente, ocorre também associada ao verbo principal de uma oração, expressando o que Seki (2000, p. 146-147) denomina de "modalidade desiderativa", e compondo um "predicado complexo monooracional" que, com a diferença de ser interpretado pela autora como um sufixo, ocorre na mesma posição que o verbo 'saber' do Guajá, isto é, “acrescenta-se imediatamente após o verbo principal, (...) os dois verbos da construção requerem um mesmo sujeito, e a raiz verbal sufixada não tem especificação para pessoa" (Seki, 2000, p. 147).

O mesmo ocorre com o Tenetehara (Duarte et al., 2018). A raiz cognata putar 'querer/desejar' ainda é utilizada como verbo lexical, sendo associada às marcas de

uma relação de argumento e predicado, isto é, construções com semântica de complementação. Esses são exatamente os dois casos identificados no Guajá.

Revista Moara, n. 58, jan-jul 2021 ISSN: 0104-0944 
pessoa mas, paralelamente, também ocorre associada ao verbo lexical, sem marca de pessoa, expressando, segundo a interpretação de Duarte et al. (2018), tempo futuro:

$$
\begin{array}{lllll}
\text { a-ha-putar } & \text { ka'a } & \text { r-upi } & \text { ihe } & \text { ri'i } \\
\text { 1SG.I-ir-FUT } & \text { mata } & \text { REL-para } & \text { 1SG } & \text { CERT }
\end{array}
$$

'Eu vou para a mata com certeza.' (adaptado de Camargos et al., 2019, p. 834)

Argumento a favor de que "os exemplos das línguas Kamayurá e Tenetehara ilustram fases anteriores do processo de gramaticalização por que já passou a língua Guajá” (Magalhães 2019:911), isto é, no Guajá, com o desaparecimento do verbo lexical mata 'querer', a posição de V2 que ele ocupava na SVC deixa de existir e sua raiz torna-se apenas um elemento com função gramatical, uma partícula de aspecto projetivo, que como tal, também sofre desgaste fonológico, passando a ta. A identificação de verbos lexicais plenos cognatos em línguas relacionadas, além da forma fonética dissilábica mata encontrada ainda na fala do mais velhos, permite supor que tal mudança é relativamente recente na língua.

Sobre esse percurso diacrônico, Givón (1995) refere-se ao surgimento de marcadores auxiliares de TAM a partir de construções seriais como um fenômeno atestado em várias línguas, como Tok Pisin e Supyire, uma língua Senufu falada no Mali.

Dessa forma, a estrutura já mais comprimida de um predicado complexo formado pela SVC, em que a ligação entre os verbos é estreita a ponto de configurar uma sentença monoclausal, tem potencial de avançar ainda mais no processo de compressão, a exemplo do que já ocorreu com mata 'querer' $\rightarrow$ ta PROJ, e tornar-se uma sentença simples.

\section{Considerações finais}

Diferente de outras línguas da FTG que registram SVCs originárias de construções de gerúndio, mudanças diacrônicas envolvendo processos de elaboração e compressão nesse tipo de estrutura subordinada alcançaram resultados diferentes no Guajá. Ao mesmo tempo, uma possível SVC, atualmente restrita a quatro verbos ( $k w a$ 
'saber', pa 'terminar', manahỹ 'estar errado/feio/ruim/imperfeito' e parahỹ 'estar certo/bonito/bom/perfeito') também pode ser identificada e aparentemente demonstra potencial de compressão.

A elaboração é evidenciada pela mudança de uma oração subordinada adverbial (gerúndio) que expressava sequência de eventos para uma sequência assindética de predicados independentes entre si (parataxe). Num processo gradativo (ainda rastreável) de afrouxamento da ligação entre oração principal e subordinada surgiram as orações coordenadas que expressam eventos distintos, em que os verbos não são marcados por qualquer material morfofonológico e não compartilham actantes, TAM ou polaridade.

Já o processo de compressão na ligação entre as orações de uma sentença ocorre em duas diferentes estruturas no Guajá.

De um lado os verbos posicionais e de movimento que integravam as mesmas orações subordinadas adverbiais dão origem a partículas posicionais e direcionais, evidenciando a mudança da construção subordinada biclausal para um único predicado monoclausal formado por verbo + partícula. Nesse processo observamos, no nível sintático, o estreitamento máximo da integração da oração subordinada à oração principal, tendo o verbo da oração subordinada se transformado em palavra gramatical. No que se refere à dessentencialização, os componentes da antiga oração subordinada já não têm actantes, marcas de TAM e polaridade próprios, uma vez que o verbo núcleo dessas orações tornou-se um elemento gramatical da cláusula principal. Diferente do que propõe Lehmann (1989), segundo o qual a oração subordinada, no processo de dessentencialização, adquire cada vez mais propriedades nominais e no final deste processo torna-se um constituinte nominal ou adverbial de uma cláusula matricial, no Guajá a dessentencialização culmina no surgimento de uma partícula. De qualquer forma, o processo não deixa de ser o mesmo: "uma cláusula subordinada é reduzida ao seu núcleo, o predicado" (Lehmann 1989, p. 196).

O outro fenômeno de compressão atestado pelo Guajá é o da formação de partículas aspectuais a partir do V2 de uma SVC. A construção já comprimida de uma SVC, que tem características monoclausais, avança ainda mais no processo de compressão quando o verbo lexical deixa de existir e passa a figurar como um componente gramatical do antigo V1 tornando-se um constituinte da cláusula principal (dessentencialização).

Revista Moara, n. 58, jan-jul 2021 ISSN: 0104-0944 
No que diz respeito ao parâmetro "gramaticalização do predicado principal", o nível máximo de compressão seria quando o verbo da oração principal é reduzido a modais ou auxiliares (Lehmann 1989, p.196). Observa-se no Guajá, no entanto, um resultado diferente: são os verbos da oração subordinada que são gramaticalizados (em partícula), ficando o verbo da oração principal intacto. O mesmo ocorre nas SVCs, em que o V2 vai perdendo seu conteúdo lexical e tornando-se uma palavra gramatical. A meu ver, essa diferença em nada invalida a constatação de que há um evidente processo de compressão entre as orações.

Assim, levando-se em consideração os parâmetros i) o movimento de mudança de uma sentença para uma palavra no nível sintático, ii) a dessentencialização, isto é, a perda gradativa das propriedades de uma oração, e iii) a gramaticalização de predicados independentes em operadores gramaticais, podemos ilustrar os processos de elaboração e compressão descritos neste estudo da seguinte maneira:

Figura 2: Elaboração e compressão de sentenças complexas no Guajá

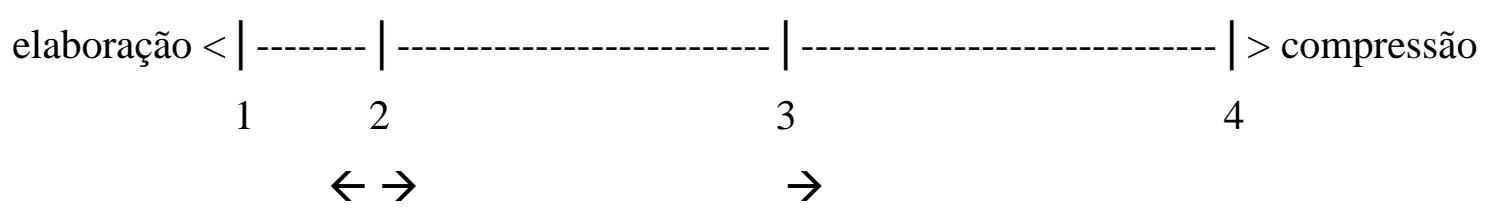

A posição 1 é ocupada pelas sentenças assindéticas de orações independentes coordenadas entre si que expressam sequência de eventos, resultantes da elaboração da ligação entre oração principal e subordinada adverbial (gerúndio).

A posição 2 é ocupada pelas orações subordinadas adverbiais (gerúndio), sentenças complexas que ilustram uma maior ligação entre as orações principal e subordinada, uma vez que compartilham o mesmo sujeito, TAM e estão interligadas pelo morfema subordinador. Elas são a fonte da elaboração que gerou as sentenças em 1 e da compressão que resultou na maior parte das sentenças em 4.

A posição 3 é ocupada pelas SVCs, construções monoclausais formadas por predicados complexos em que dois verbos com independência lexical compartilham actantes, TAM e polaridade, evidenciando o avanço no processo de compressão entre as orações. Elas são a fonte da compressão que gerou uma das estruturas em 4.

Revista Moara, n. 58, jan-jul 2021 ISSN: 0104-0944 
A posição 4 é ocupada pelas orações monoclausais, sentenças simples resultantes da gramaticalização em partículas tanto dos verbos subordinados das orações adverbiais como dos V2 das SVCs, que se tornaram uma palavra gramatical, ilustrando a etapa final de compressão da ligação entre orações no Guajá.

Agradecimentos: Quero agradecer especialmente aos amigos Takwarakỹa Awa Guajá, Hajkaramykỹa Awa Guajá e Metỹa Awa Guajá que, em uma unidade de quarentena, via vídeo conferência, forneceram os dados elicitados adicionais de que precisei para finalizar esta apresentação.

\section{Lista de abreviaturas:}

\begin{tabular}{ll}
1 & primeira pessoa \\
2 & segunda pessoa \\
3 & terceira pessoa \\
I & Série I de marcadores pessoais \\
II & Série II de marcadores pessoais \\
III & Série III de marcadores pessoais \\
CERT & certeza \\
COND & partícula condicional \\
CONS & subordinador de evento consecutivo \\
CORR & prefixo correferencial \\
CTF & partícula centrífuga 'indo' \\
DEM & demonstrativo \\
DIR & partícula direcional \\
DUB & partícula posicional \\
EMPH & ênfase \\
EXCL & exclusivo \\
FIN & subordinador de finalidade \\
FTG & Família Tupi-Guarani \\
FUT & futuro \\
GER & gerúndio \\
IMPERF & imperfectivo \\
INTS & intensidade \\
LK & sufixo de ligação 'linker' \\
LOC & locativo \\
NEG & negação \\
NMZR & nominalizador \\
POS & partícula posicional \\
PROJ & aspecto projetivo \\
RED & reduplicação \\
REFL & reflexivo \\
REL & relacional \\
RFR & sufixo referenciante \\
SER & marcador de serialização verbal \\
SG & singular \\
& \\
\hline
\end{tabular}

Revista Moara, n. 58, jan-jul 2021 ISSN: 0104-0944 


$\begin{array}{ll}\text { SN } & \text { Sintagma Nominal } \\ \text { SP } & \text { Sintagma Posposicional } \\ \text { SVC } & \text { Construção Verbal Serial } \\ \text { TAM } & \text { Tempo-Modo-Aspecto } \\ \text { TEMP } & \text { subordinador temporal } \\ \text { TOT } & \text { totalizador } \\ \text { V1 } & \text { verbo 1 de uma SVC } \\ \text { V2 } & \text { verbo 2 de uma SVC }\end{array}$

\section{REFERÊNCIAS}

AIKHENVALD, A. Y. Serial verb constructions in typological perspective. In A. Y. Aikhenvald \& R. M. W. Dixon (eds.), Serial verb constructions: A crosslinguistic typology, 1-68. Oxford: Oxford University Press, 2006.

AIKHENVALD, Alexandra Y.; DIXON, Robert M. W. (ed.). Serial verb constructions: a cross-linguistic typology. Oxford: Oxford University Press, 2006.

AIKHENVALD, Alexandra Y.; DIXON, Robert M. W. A critical assessment of Haspelmath's interpretation. Letter to the editor of Language and Linguistics Serial verb constructions, 2019.

ANCHIETA, Pe. José de. Artes de gramática da língua mais usada na costa do Brasil. São Paulo: Loyola, 1990 (edição fac-similar de Artes de grammatica da lingva mais vsada na costa do Brasil. Coimbra: Antonio de Mariz, 1595).

ANDREWS, A. D. and Manning, C. D. Complex predicates and information spreading in LFG. Stanford: Centre for the Study of Language and Information, 1999.

BALMER, W. T.; GRANT, F. C. F. A grammar of the Fante-Akan language. London: Atlantis Press, 1929.

BRIL, I. Complex nuclei in Oceanic languages? Contribution to an areal typology. Complex predicates in Oceanic languages. Studies in the dynamics of binding and boundness, Isabelle Bril \& Françoise Ozanne-Rivierre (eds.), 1-48. Berlin: Mouton de Gruyter, 2004.

CABRAL, A. S. A. C. Algumas evidências linguísticas de parentesco genético do Jo'é com línguas Tupí-Guaraní. Moara, revista dos Cursos de Pós-Graduação em Letras, n.4, Belém: UFPA, 1996. p. 47-76.

CABRAL, A. S. A. C.; RODRIGUES, A. D. O desenvolvimento do gerúndio e do subjuntivo em Tupí-Guaraní. In: RODRIGUES, Aryon Dall'Igna; CABRAL, Ana Suely 
Arruda Câmara (org.). Novos estudos sobre línguas indígenas. Brasília: Editora da UnB, 2005. p. 47-58.

CAMARgOS, Q. F.; CASTRO, R. C.; TESCARI NETO, A. Partículas de Final de Sentença (PFS): uma análise cartográfica por fases sobre o sistema da língua Tenetehára. Boletim do Museu Paraense Emílio Goeldi. Ciências Humanas, Belém, v. 14, n. 3, set.-dez. 2019. p. 827-855.

CHRIStaller, J.G. A grammar of the Asante and Fante languages called Tshi (Chwe, Twi). Basel: Basel Evangelical Missionary Society. 1875.

CROWLEY, T. Serial verb constructions in Paamese. Studies in Language 11, 1987. p. $35-84$.

DIXON, R. M. W. Serial verb constructions: conspectus and coda. In: A. Y. Aikhenvald \& R. M. W. Dixon (eds.), Serial verb constructions: A crosslinguistic typology. Oxford: Oxford University Press. 2006. p 1-68.

DUARTE, Fábio B. Negação e movimento do verbo na língua Tembé. In: Cabral, A. S. A. C. \& Rodrigues, A. D. (orgs) línguas indígenas brasileiras: fonologia, gramática e história, t. I. Belém: UFPA. 2001. p. 374-384.

DUARTE, Fábio Bonfim; CAMARGOS, Quesler Fagundes; CASTRO, Ricardo Campos; SILVA, Cíntia Maria Santana; GUAJAJARA, Marina da Silva. Coletânea de narrativas Guajajára, v. 1. Belo Horizonte: FALE: UFMG. 2018.

DURIE, Mark. Grammatical Structures in Verb Serialization. Complex predicates. Alex Alsina; Joan Bresnan \& Peter Sells (eds.). Standford CA: CSLI, 1997. p. 289-354.

FIGUEIRA, Luís. Arte de grammatica da língua brasílica. Lisboa: M. deslandes, 1687. Reprodução facsimilar: Leipzig: Teubner, 1878.

FOLEY, William A. Events and serial verb constructions. In: Mengistu Amberber, Brett Baker \& Mark Harvey (eds.), Complex predicates: Cross-linguistic perspectives on event structure. Cambridge: Cambridge University Press, 2010. p. 79-109.

FOLEY, W. A.; OLSON, M. Clausehood and verb serialisation. In: J. Nichols; A. C. Woodbury (eds). Grammar inside and outside the clause. Cambridge: Cambridge University Press, 1985. p. 17-60.

GARCIA, Uirá F.; MAGALHÃES, Marina M. S. (2021). Instituto Socio Ambiental. 2021. Disponível em: Povos indígenas no Brasil (Guajá): https://pib.socioambiental.org/pt/Povo:Guajá. Acesso em 4 de maio de 2021.

Revista Moara, n. 58, jan-jul 2021 ISSN: 0104-0944 
GIVÓN, T. On the Verbal Origin of the Bantu Suffixes. Studies in African Linguistics 2. 1971. p. 145-163.

GIVÓN, T. Some substantive issues concerning verb serialisation: grammatical vs cognitive packaging. In: Claire Lefebvre (ed.), Serial verbs: Grammatical, comparative and cognitive approaches. Amsterdam: Benjamins. 1991. p. 137-84.

GIVÓN, Talmy. Functionalism and grammar. Amsterdam: John Benjamins Publishing Company, 1995.

JENSEN, Cheryl. Comparative Tupí-Guaraní Morpho-syntax. In: Desmond Derbyshire and Geoffrey Pullum (eds.). Handbook of Amazonian languages. Berlin: Mouton de Gruyter, 1998. p. 490-603.

KAKUMASU, James. Urubu-Kaapor. Handbook of Amazonian languages, Vol.1. Ed. By Derbyshire and Pullum. Berlin: Mouton de Gruyter. 1986. p. 326-403.

LAW, P.; VEENSTRA, T. On the structure of serial verb constructions. Linguistic Analysis 22. 1992. p. 185-217.

LEHMANN, Christian. Towards a typology of clause linkage. In: John Haiman; Sandra Thompson (eds.). Clause Combining in Grammar and discourse. Amsterdam/Philadelphia: Benjamins. 1989. p. 181-226.

LEITE, Yonne. Para uma tipologia do Tapirape. Comunicação apresentada no II Encontro Nacional da Associação Nacional de Pós-Graduação e Pesquisa em Letras e Linguística. Rio de Janeiro, 1978.

MAGAlHÃES, Marina M. S. Sobre a morfologia e a sintaxe da língua Guajá: família Tupí-Guaraní. Tese (Doutorado em Linguística) - Universidade de Brasília, Brasília, 2007.

MAGALHÃES, Marina M. S. A gramaticalização de verbos em partículas. Boletim do Museu Paraense Emílio Goeldi. Ciências Humanas, Belém, v. 14, n. 3, set./dez. 2019.

NAVARRO, Eduardo de Almeida. Método Moderno de Tupi Antigo: a língua do Brasil dos primeiros séculos. Petrópolis, RJ: Vozes, 1998.

NOONAN, M. Complementation. In: T. Shopen (ed.). Language Typology and Syntactic Description. Complex Constructions. Vol. II, Cambridge: Cambridge University Press. 1985. p. 42-140.

PRAÇA, Walkiria N. Morfossintaxe da língua Tapirapé: família Tupí-Guaraní. 2007. Tese (Doutorado em Linguística) - Universidade de Brasília, Brasília, 2007.

RODRIGUES, Aryon D. Estrutura do Tupinambá, s.d., manuscrito.

Revista Moara, n. 58, jan-jul 2021 ISSN: 0104-0944 
RODRIGUES, Aryon D. Morfologia do verbo em Tupi, In: Letras, n.1. Curitiba, 1953. p.121-152

RODRIGUES, Aryon D. Relações internas na família lingüística Tupí-Guaraní. Revista de Antropologia, vol. 27/28. São Paulo: USP, 1984/1985. p. 33-53.

ROSE, Françoise. The origins of serialization. The case of Emerillon. Studies in Language. 33:3. John Benjamins Publishing Company, 2009. p.644-684.

RUIZ DE MONTOYA, A. Arte, y bocabulario de la lengua guarani.Madri, 1640. Reprodução facsimilar integral: Madri: Cultura Hispánica. 1994. Reprodução facsimilar só da Arte: Assunção: Centro de Estudios Paraguayos “Antonio Guasch”.1993.

SEKI, Lucy. Gramática do Kamaiurá: língua Tupi-Guarani do Alto Xingu. Campinas: Editora da UNICAMP; São Paulo: Imprensa Oficial, 2000.

SHIBATANI, Masayoshi. On the form of complex predicates - Toward demystifying serial verbs. Form and function in Language Research, Johannes Helbrecht; Yoko Nishina; Yong-Min Shin, et al. (eds). Berln: Mouton de Gruyter. 2009.

STADEN, M.; GER P. R. Serial verb constructions in a linguistic area. In: Gunter Senft (ed.), Serial verb constructions in Austronesian and Papuan languages (Pacific Linguistics, 594). Canberra: Pacific Linguistics. 2008. p. 17-54.

STEWART, J. M. Some restrictions on objects in Twi. Journal of African Languages 2. 1963. p. 145-9.

VELAZQUEZ-CASTILLO, Maura. Serial Verb Constructions in Paraguayan Guarani. IJAL 70(2), April, 2004. p. 187-214.

WESTERMANN, D. H. Grammatik der Ewe-Sprache. Berlin: Diedrich Reimer. 1907.

WESTERMANN, D. H. A study of the Ewe language. London: Oxford University Press. 1930.

ZWICKY, A. What are we talking about when we talk about serial verb constructions?. Joseph and Zwicky (eds.). 1990. p. 1-13 